\title{
Preservice Teachers' Sense of Efficacy and Its Sources
}

\author{
Sunjin Oh \\ Department of Curriculum and Instruction, Iowa State University, Ames, USA. \\ Email:sunjin@iastate.edu \\ Received November $18^{\text {th }}, 2010$; revised January $20^{\text {th }}, 2011$; accepted February $25^{\text {th }}, 2011$.
}

\begin{abstract}
The purpose of this study was to examine several potential sources of preservice teachers' perceptions of their teaching efficacy during their reading and writing lessons. More specifically, the study explored the relationship between the sources of preservice teachers' self-efficacy and teachers' perception of efficacy in the areas of instructional strategies, classroom management, and student engagement. Forty-three preservice teachers in pre-literacy methods courses and fourteen in post-literacy methods courses completed the survey, which consisted of the Teacher Sense of Efficacy Scale (TSES) and Teaching Efficacy Sources Inventory. Paired t-test results showed that preservice teachers' teaching efficacy increased in the three subscales of instructional strategies, classroom management, and student engagement by the end of the literacy method courses. Efficacy for instructional strategies, classroom management, and student engagement were highly intercorrelated with each other in the pre-test data. The results of multiple regression analysis indicated that personality characteristics, capabilities, motivation, enactive mastery experiences with social/verbal persuasion, and physiological/affective state were significant predictors when efficacy for classroom management was the dependent variable in the post-test data. Findings of this study revealed that preservice teachers' personality, motivation, and capabilities were one of the important sources to improve their teaching efficacy, in congruence with previous research (Poulou, 2007; Yeung \& Watkins, 2000).
\end{abstract}

Keywords: Preservice Teachers' Teaching Efficacy, Sources of Teaching Efficacy, Preservice Teachers' Personality Characteristics, Capabilities, Motivation

\section{Introduction}

As teacher efficacy has emerged as an important construct in teacher education over the past 25 years, issues involving teacher efficacy have become increasingly important. There have been renewed demands to improve children's academic achievement and to follow the intent of the No Child Left Behind legislation. Increased demands have been noted especially in the domain of reading because of a change in reading teacher education that has been mandated by the Reading First initiative (US Department of Education, 2002).

Teacher efficacy has been defined as a teacher's "judgment of his or her capabilities to bring about desired outcomes of student engagement and learning, even among those students who may be difficult or unmotivated" (Tschannen-Moran \& Woolfolk Hoy, 2001: p. 783). Teachers' efficacy beliefs are associated with teachers' willingness to devote more time to academic instruction and take greater responsibility for education students who have learning difficulties (Dembo \& Gibson, 1985). In addition, more efficacious preservice teachers were less interventionist toward classroom management after examining the multivariate relationships between teacher efficacy and task analysis variables as predictors of classroom beliefs about control (Henson, 2001).

Given that teacher efficacy is related to teacher effectiveness and appears to influence students' achievement, attitude, and affective growth, it is of great interest to explore the development of efficacy beliefs among teachers. In addition, given the importance of a strong sense of efficacy for optimal motivation in teaching, exploring factors that contribute to the initial de- velopment of preservice teachers' efficacy will help them develop strong efficacy beliefs early in their career.

Experienced teachers are generally provided with the source of information, including an abundance of mastery experience, to develop their teaching efficacy. However, prospective teachers generally do not have this source of information, at least not until they have their teaching practice in school in which they receive emotional arousal and verbal persuasion, including performance feedback from supervisors, classroom teachers, and other peers (Chan, 2008; Tschannen-Moran \& Woolfolk Hoy, 2007). With the differential amount of information from these sources, as well as different experience of teaching practice, preservice teachers might have different levels of belief in their teaching self-efficacy. The overwhelming majority of research in the area of teacher efficacy has been conducted on inservice teachers, and relatively little is known about the knowledge base in this area among preservice teachers.

In addition, according to previous research studies of preservice teachers' self-efficacy, the value and power of teachers' sense of efficacy has been well established in the literature, but the sources of teachers' efficacy beliefs has not been established (Anderson \& Betz, 2001; Poulou, 2007; TschannenMoran \& Woolfolk Hoy, 2007). For example, Anderson and Betz (2001) have argued that little research has focused on the sources of self-efficacy, in contrast to the amount of research on correlates or outcomes of self-efficacy. Tschannen-Moran and Woolfolk Hoy (2007: p. 953) state that "it is of both theoretical and practical importance to understand the sources teachers tap when making judgments about their capability for instruction". 


\section{Theoretical Framework}

This study is based on the theoretical framework of self-efficacy developed by Bandura's (1977) social cognitive theory because most researchers in psychology and education attribute the concept of teacher efficacy to this theoretical framework. Bandura (1997: p. 3) defines perceived self-efficacy as "beliefs in one's capabilities to organize and execute the courses of action required to produce given attainments". Self-efficacy has to do with self-perception of competence rather than actual level of competence. People regularly overestimate or underestimate their actual capabilities, and these estimations may have consequences for the courses of action they choose to pursue or the effort they exert in those pursuits.

Bandura (1997) suggests that self-knowledge about one's efficacy is based on four sources of information: 1) performance or mastery, 2) vicarious experiences, 3 ) verbal or social persuasion, and 4) physiological and/or emotional states. Performance or mastery refers to a teacher's experience in terms of success and failure. The most influential source of efficacy information is enactive mastery, which provides authentic evidence of the teacher's performance in the classroom and school setting, with success leading to enhanced self-efficacy and failure to reduced self-efficacy. Vicarious experiences occur through the observation of others succeeding or failing. Poulou (2007) said that when there are no absolute measures of adequacy and individuals' activities, people assess their ability through comparisons with others in similar situations. Thus, modeling serves as an effective tool for promoting a sense of personal efficacy. Verbal persuasion stems from activities such as talks, course work, professional development workshops, and feedback about achievement, and these have a positive influence that give teachers information about the task of teaching. Physiological and/or emotional states impact how people interpret their physical and emotional reactions. For example, tension and stress are often interpreted by individuals as signs of a lack of ability or of poor performance.

\section{Purpose of This Study}

The importance of teaching efficacy gives rise to the need to investigate the factors that influence prospective teachers' perceptions of teaching efficacy. Given the recognized importance of self-efficacy among prospective teachers, it is essential to research the factors that serve as sources of prospective teacher efficacy. Extending Bandura's four sources of efficacy beliefs-performance or mastery, vicarious experiences, verbal or social persuasion, and physiological and/or emotional states, the author wondered what other sources impact preservice teachers' self-efficacy. The purpose of this study was to examine several potential sources of preservice teachers' perceptions of their teaching efficacy during their reading and writing lessons. More specifically, the study explored the relationship between the sources of preservice teachers' self-efficacy and teachers' perception of efficacy in the areas of instructional strategies, classroom management, and student engagement.

\section{Methodology}

\section{Participants}

Preservice teachers who were enrolled in literacy method courses during Summer 2009 at a Midwestern research-extensive university in the United States were invited to participate in this study. Literacy method courses were paired with a literacy block practicum, which provides an opportunity for preservice teachers to gain practical classroom experience in local elementary school settings. During the summer semester, preservice teachers who attended literacy methods courses for five weeks, for four days a week, were assigned to a classroom five days a week for three weeks for their literacy block practicum.

\section{Survey Instruments}

The survey consisted of three parts. The first part, the Teacher Sense of Efficacy Scale (TSES), is a 24-item measure developed by Tschannen-Moran and Woolfolk Hoy (2001). This scale consists of three dimensions: instructional strategies, classroom management, and student engagement. The language of the questions in the original TSES scale was adapted, as it referred to preservice teachers' self-efficacy beliefs about literacy areas. As an example of the adaptation of such an item: "To what extent can you use a variety of assessment strategies?" was changed to "To what extent can you use a variety of assessment strategies in your reading and writing lessons?" The 9-point continuum in the original version of TSES were revised as a 5-point Likert range in this study, from $1=$ not at all to $5=$ a great deal. The second part, the Teaching Efficacy Sources Inventory developed by Poulou (2007), comprised 30 items in the seven categories of personality characteristics, capabilities, motivation, enactive mastery with social/verbal persuasion, vicarious experiences, university training, and physiological/affective state. This Inventory was developed based on interviews with 32 Greek 4th-year student teachers. For each statement, respondents rated the sources of teaching efficacy on Likert-type items, with values ranging from strongly agree (5) to strongly disagree (1). Demographic variables, such as gender, ethnicity, grade point average, and completed teaching practicum hours, were included in the last section.

\section{Data Collection Procedures}

The survey questionnaire was distributed to preservice teachers when the author visited the literacy method class at the beginning of semester for the pre-test. Preservice teachers were informed of the purpose of this study and procedures as well as timelines for participation in this study at the beginning of the literacy method courses for pre-test measures of teacher selfefficacy. The author sent the survey questionnaire to preservice teachers at the end of the literacy block practicum for post-test measures of teacher self-efficacy, using Qualtrics, which was the online survey method provided by university, and this participation was voluntary. All participants who enroll in the literacy method class during Summer 2009 were invited to complete anonymous surveys that include the Teachers' Sense of Efficacy Scale (TSES) and Teaching Efficacy Sources Inventory.

\section{Results}

The Teacher Sense of Efficacy Scale (TSES) originally had two forms, a long form with 24 items, with 8 items for each of three subscales, and a short from with 12 items, with 4 items 
for each of three subscales but the 24-item long form of TSES was used in this study. The reliability for the 24-item scale was 0.94 and for the 12-item scale was 0.90 in the original TSES. The reliability of adapted TSES used in this study, as it referred to preservice teachers' self-efficacy beliefs about literacy areas, was $\alpha=0.97$ for the pre-test and was $\alpha=0.86$ for the post-test. The results of Cronbach's $\alpha$ reliability coefficients of this study demonstrated an adequate level of reliability and indicated a high level of internal consistency among the items of TSES.

Forty-three preservice teachers completed the pre-test survey and 14 completed the post-test survey; 9 preservice teachers responded to both the pre- and post-test measures. In the pretest data, the participants were primarily white females: 35 females (81\%) and 8 males (19\%); 41 white (96\%), 1 African-American or Black (2\%), and 1 Hispanic (2\%). Mean TSES scores for both pre- and post-literacy methods courses are presented in Table 1. It is not appropriate to conduct $t$-tests comparing pre-course and post-course scores because 43 preservice teachers responded to the pre-test while only 14 preservice teachers responded to the post-test, but descriptively preservice teachers' self-efficacy in the three subscales of instructional strategies (from $M=3.59$ to $M=4.09$ ), classroom management (from $M=3.65$ to $M=4.12$ ), and student engagement (from $M=3.57$ to $M=3.84$ ) increased by the end of the literacy method courses (Table 1).

Table 1.

Mean scores on pre-test $(N=43)$ and post-test $(N=14)$ preservice teachers' ratings on TSES.

\begin{tabular}{|c|c|c|}
\hline Item & Pre Mean & Post Mean \\
\hline Efficacy for instructional strategies & 3.59 & 4.09 \\
\hline 1. To what extent can you use a variety of assessment strategies in your reading and writing lessons? & 3.77 & 4.14 \\
\hline $\begin{array}{l}\text { 2. To what extent can you provide an alternative explanation or example when students are confused about your reading } \\
\text { and writing lessons? }\end{array}$ & 3.67 & 4.14 \\
\hline 3. To what extent can you craft good questions about teaching reading and writing for your students? & 3.72 & 4.21 \\
\hline 4. How well can you implement alternative strategies for your reading and writing lessons? & 3.65 & 4.07 \\
\hline 5. How well can you respond to difficult questions about your reading and writing lessons from your students? & 3.42 & 4.00 \\
\hline 6. How much can you do to adjust your reading and writing lessons to the proper level for individual students? & 3.42 & 4.14 \\
\hline 7. To what extent can you gauge student comprehension of what you have taught about reading and writing? & 3.60 & 3.86 \\
\hline 8. How well can you provide appropriate challenges for very capable students in reading and writing lessons? & 3.44 & 4.14 \\
\hline Efficacy for classroom management & 3.65 & 4.12 \\
\hline 9. How much can you do to control disruptive behavior in the classroom during your reading and writing lessons? & 3.67 & 4.21 \\
\hline 10. How much can you do to get children to follow classroom rules during your reading and writing lessons? & 3.74 & 4.14 \\
\hline 11. How much can you do to calm a student who is disruptive or noisy during your reading and writing lessons? & 3.56 & 4.00 \\
\hline $\begin{array}{l}\text { 12. How well can you establish a classroom management system with each group of students for your reading and writing } \\
\text { lessons? }\end{array}$ & 3.67 & 4.14 \\
\hline 13. How well can you keep a few problem students from ruining an entire reading and writing lesson? & 3.42 & 4.00 \\
\hline 14. How well can you respond to defiant students in reading and writing lessons? & 3.26 & 4.00 \\
\hline 15. To what extent can you make your expectation clear about student behavior during your reading and writing lessons? & 3.98 & 4.29 \\
\hline 16. How well can you establish routines to keep activities running smoothly in your reading and writing lessons? & 3.88 & 4.14 \\
\hline Efficacy for student engagement & 3.57 & 3.84 \\
\hline 17. How much can you do to get students to believe they can do well in their reading and writing schoolwork? & 3.91 & 4.36 \\
\hline 18. How much can you do to help your students value learning about reading and writing? & 3.77 & 3.86 \\
\hline 19. How much can you do to motivate students who show low interest in their reading and writing schoolwork? & 3.60 & 3.79 \\
\hline 20. How much can you assist families in helping their children do well in reading and writing? & 3.43 & 3.36 \\
\hline 21. How much can you do to improve the understanding of reading and writing of a student who is failing? & 3.51 & 3.71 \\
\hline 22. How much can you do to help your students think critically about reading and writing? & 3.44 & 3.93 \\
\hline 23. How much can you do to foster student creativity in reading and writing? & 3.77 & 4.07 \\
\hline 24. How much can you do to get through to the most difficult students in your reading and writing lessons? & 3.23 & 3.64 \\
\hline
\end{tabular}


Mean scores for the 9 preservice teachers who answered both pre- and post-test items were significantly higher on the posttest than on the pre-test for each of the three subscales. Paired $t$-tests showed that there were significant differences on the three subscales (Table 2).

Multiple regression analysis was conducted to investigate the sources of teaching efficacy that could influence preservice teachers' perception of self-efficacy in both pre- and post-test. None of the sources of teaching efficacy were significant predictors of preservice teachers' self-efficacy in the pre-test data, largely due to the limited number of observations and consequently larger standard deviations, as well as possible multicollinearity. However, personality characteristics, capabilities, motivation, enactive mastery experiences with social/verbal persuasion, and physiological/affective state were significant predictors when efficacy for classroom management was the dependent variable in the post-test data (see Table 3 ). When efficacy for instructional strategies was the dependent variable, capabilities turned out to be a significant predictor $(\beta=-1.50, p$ $<0.05)$. The negative values for Beta may be a function of collinearity, which would be expected with the small sample size in the post-test $(N=14)$.
Accordingly, Pearson product-moment correlations were calculated to determine whether any statistically significant relationships exist between sources of teaching efficacy and perceived efficacy for instructional strategies, classroom management, and student engagement (Table 4). The three selfefficacy subscales were highly intercorrelated with each other in the pre-test data. This implies that the three self-efficacy dimensions together measure a single underlying latent construct of self-efficacy. Efficacy for instructional strategies was related to efficacy for classroom management in the post-test. In the pre-test, enactive mastery experiences with social and verbal persuasion were significantly $(p<0.05)$ related to both efficacy for instructional strategies $(r=0.40)$ and efficacy for student engagement $(r=0.38)$. Sources of university training were significantly related to both efficacy for instructional strategies $(r=0.36)$ and efficacy for student engagement $(r=$ 0.32 ). None of the sources was significantly related to efficacy for classroom management. There was no relation in the posttest between any of the sources of teaching efficacy and preservice teachers' self-efficacy, largely due to the limited number of observations.

Table 2.

Paired t-test outcome of pre- and post-test scores of nine preservice teachers on TSES.

\begin{tabular}{|c|c|c|c|c|c|c|c|c|}
\hline & & \multirow{2}{*}{ Mean } & \multirow{2}{*}{$N$} & Mean & Standard & Standard & \multirow{2}{*}{$t$} & \multirow{2}{*}{$p$-value } \\
\hline & & & & Difference & Deviation & Error Mean & & \\
\hline \multirow{2}{*}{ Instructional strategies } & Posttest & 3.96 & 9 & 0.9 & 0.36 & 0.12 & 7.46 & $0.001 * *$ \\
\hline & Pretest & 3.06 & 9 & & & & & \\
\hline \multirow{2}{*}{ Classroom management } & Posttest & 4.06 & 9 & 0.71 & 0.71 & 0.24 & 3.01 & $0.017^{*}$ \\
\hline & Pretest & 3.35 & 9 & & & & & \\
\hline \multirow{2}{*}{ Student engagement } & Posttest & 3.76 & 9 & 0.61 & 0.5 & 0.17 & 3.68 & $0.006^{* *}$ \\
\hline & Pretest & 3.15 & 9 & & & & & \\
\hline
\end{tabular}

${ }^{* *} p<0.01 ;{ }^{*} p<0.05$

Table 3.

Beta regression coefficients for sources of teaching efficacy as predictors of efficacy IS, CM, and SE.

\begin{tabular}{|c|c|c|c|c|c|c|}
\hline \multirow{2}{*}{ Sources } & \multicolumn{2}{|c|}{ Instructional strategies } & \multicolumn{2}{|c|}{$\begin{array}{l}\text { Outcome measures } \\
\text { Classroom management }\end{array}$} & \multicolumn{2}{|c|}{ Student engagement } \\
\hline & $\begin{array}{c}\text { Standardized } \\
\text { Coefficients Beta }\end{array}$ & Sig. & $\begin{array}{c}\text { Standardized } \\
\text { Coefficients Beta }\end{array}$ & Sig. & $\begin{array}{c}\text { Standardized } \\
\text { Coefficients Beta }\end{array}$ & Sig. \\
\hline Personality characteristics & -0.76 & 0.37 & -2.75 & $0.01 *$ & -0.21 & 0.89 \\
\hline Capabilities/skills & -1.50 & $0.03 *$ & -1.08 & $0.05^{*}$ & -0.38 & 0.70 \\
\hline Motivation & 1.73 & 0.19 & 4.08 & $0.01 *$ & 0.44 & 0.85 \\
\hline Enactive mastery with social/verbal persuasion & -0.28 & 0.67 & -1.58 & $0.04 *$ & -0.98 & 0.45 \\
\hline Vicarious experience & -0.21 & 0.71 & 1.08 & 0.07 & 1.01 & 0.37 \\
\hline Physiological/affective state & -1.66 & 0.09 & -3.27 & $0.01 *$ & -1.40 & 0.39 \\
\hline University training & 0.87 & 0.08 & 0.37 & 0.31 & 0.90 & 0.29 \\
\hline
\end{tabular}


Table 4.

Correlation analysis of preservice teachers' sense of efficacy and sources in both pre- $(N=43)$ and post-test $(N=14)$.

\begin{tabular}{|c|c|c|c|c|c|c|c|c|c|c|}
\hline Pre-test & 1 & 2 & 3 & 4 & 5 & 6 & 7 & 8 & 9 & 10 \\
\hline 1 & 1.00 & & & & & & & & & \\
\hline 2 & $0.71 * *$ & 1.00 & & & & & & & & \\
\hline 3 & $0.83 * *$ & $0.77 * *$ & 1.00 & & & & & & & \\
\hline 4 & 0.23 & 0.18 & 0.26 & 1.00 & & & & & & \\
\hline 5 & 0.19 & 0.22 & 0.20 & $0.76^{* *}$ & 1.00 & & & & & \\
\hline 6 & 0.00 & 0.00 & 0.09 & $0.35^{*}$ & 0.02 & 1.00 & & & & \\
\hline 7 & $0.40^{* *}$ & 0.27 & $0.38^{*}$ & $0.48^{* *}$ & $0.35^{*}$ & 0.14 & 1.00 & & & \\
\hline 8 & 0.18 & 0.10 & 0.02 & -0.05 & -0.14 & -0.19 & 0.16 & 1.00 & & \\
\hline 9 & -0.07 & -0.16 & -0.05 & -0.16 & 0.01 & 0.10 & -0.39 & -0.13 & 1.00 & \\
\hline 10 & $0.36^{*}$ & 0.15 & $0.32^{*}$ & $0.31^{*}$ & 0.13 & 0.22 & $0.49^{* *}$ & 0.05 & -0.04 & 1.00 \\
\hline \multicolumn{11}{|l|}{ Post-test } \\
\hline 1 & 1.00 & & & & & & & & & \\
\hline 2 & $0.54^{*}$ & 1.00 & & & & & & & & \\
\hline 3 & 0.41 & 0.22 & 1.00 & & & & & & & \\
\hline 4 & -0.18 & 0.01 & -0.37 & 1.00 & & & & & & \\
\hline 5 & -0.19 & 0.26 & -0.16 & $0.72 * *$ & 1.00 & & & & & \\
\hline 6 & -0.23 & -0.08 & -0.36 & $0.84^{* *}$ & $0.70^{* *}$ & 1.00 & & & & \\
\hline 7 & 0.29 & -0.06 & 0.33 & 0.00 & 0.11 & 0.18 & 1.00 & & & \\
\hline 8 & -0.15 & -0.34 & 0.17 & -0.29 & -0.34 & -0.02 & $0.67^{*}$ & 1.00 & & \\
\hline 9 & -0.17 & -0.47 & -0.01 & -0.32 & -0.35 & 0.14 & 0.02 & 0.47 & 1.00 & \\
\hline 10 & 0.22 & -0.18 & 0.05 & 0.12 & 0.21 & 0.41 & $0.69^{*}$ & 0.42 & 0.19 & 1.00 \\
\hline
\end{tabular}

Note: 1 = Efficacy for instructional strategies, $2=$ Efficacy for classroom management, $3=$ Efficacy student engagement, $4=$ Personality, $5=$ Capabilities, $6=$ Motivation, $7=$ Enactive mastery with social/verbal persuasion, $8=$ Vicarious experiences, $9=$ Physiological/affective state, $10=$ University training; ${ }^{*} p<0.01 ;{ }^{*} p<0.05$.

\section{Discussion}

The purpose of this study was to examine the variables that impact preservice teachers' perceptions of their teaching efficacy during their reading and writing lessons. Extending Bandura's four sources of efficacy beliefs - performance or mastery experiences, vicarious experiences, verbal or social persuasion, and physiological and/or emotional states - this study explored what other sources may impact preservice teachers' sense of efficacy.

The results of multiple regression analysis showed that personality characteristics, capabilities, motivation, enactive mastery experiences with social/verbal persuasion, and physiological/affective state were significant predictors of efficacy for classroom management for TSES post-scores. Additionally, when efficacy for instructional strategies was the dependent variable, capabilities turned out to be a significant predictor. The findings from this study are consistent with earlier research conducted by Poulou (2007) that highlighted the importance of student teachers' personality characteristics, capabilities, and motivation as potential sources of teaching efficacy. Bandura (1997) did not identify those as important sources of information that teachers consider when making self-efficacy judgments. Although little research has examined the relationship between teacher efficacy and personality types of teachers, Erdle, Murray and Rushton (1985) found that the teacher personality traits and classroom teaching behaviors were significant correlates of students' ratings of their college teachers' effectiveness. They found that the effective university instruc- tors exhibited two types of personality traits: (1) Achievement Orientation, such as dominance, intelligence, leadership, and (2) Interpersonal Orientation, such as supportiveness, non-authoritarianism, and non-defensiveness. Poulou (2007: p. 212) mentioned that "the more student teachers perceived themselves as possessing specific personality characteristics and teaching capabilities, the more they felt efficacious in implementing instructional and discipline strategies and involving pupils in the learning process".

Overall, findings of this study also revealed that preservice teachers' motivation and capabilities were one of the important sources to improve their teaching efficacy, in congruence with previous research (Poulou, 2007; Yeung \& Watkins, 2000). Yeung and Watkins (2000) found that the development of teaching efficacy should partly be attributed to the student teachers' capability, which was acquired mainly through their teaching and observations of pupils' learning as well as confidence in dealing with daily matters.

Several limitations should be acknowledged in interpreting results from this study. First, among the limitations of this research are the different numbers of participants in the pre-test and post-test, and that the small sample size came from in one institution; 43 preservice teachers responded to the pre-test while only 14 preservice teachers responded to the post-test. Only 9 preservice teachers who provided identification answered both pre- and post-test items. Thus, caution must be exercised in generalizing from the results based on this small sample of preservice teachers from only one teacher preparation program who were enrolled in literacy method courses at a 
Midwestern research-extensive university in the United States. However, this study should be interpreted as a preliminary phase of a broader stream of research to explore the sources of preservice teachers' efficacy and changing levels of their self-efficacy beliefs.

The findings reported here should be interpreted as the results of a pilot study conducted to verify the TSES instrument and Teaching Efficacy Sources Inventory. The Teaching Efficacy Sources Inventory used in this study was developed based on 4th-year student teachers' data from two pedagogical departments in Greece. Extending these previous measures to a substantially different context, the participants in this study were preservice teachers who were enrolled in their first or second literacy methods courses at a midwestern state university in the United States and who have not yet conducted their student teaching. Thus, caution is needed in generalizing the results of this study to preservice teachers who were trained as teacher candidates in teacher preparation program in the United States. Contextual variables contributing to analysis of the teaching task consequently would play a stronger role in student teachers' sense of efficacy than for more experienced teachers. So, future research could examine what aspects of the teaching environment and context affect novice teachers' sense of efficacy. There is a need for greater understanding about how the various kinds of context variables, such as school level and setting, the quality of the school facilities, the availability of teaching resources, and interpersonal support from parents and the community, are linked to higher teaching efficacy.

\section{Conclusion}

In sum, the findings of this study revealed potential sources of preservice teachers' sense of efficacy that were not included in previous measurement inventories, such as personality characteristics, capabilities/skills, and motivation to improve preservice teachers' teaching efficacy. Notwithstanding the fact that it is necessary to understand more and less important sources that teachers consider when making efficacy judgments about their capability for instruction and classroom management, little research has examined the various potential variables that influence teachers' sense of efficacy. The results of this study have extended the results of Bandura's (1997) previous research, in which the four experiential sources of personal performance accomplishments, vicarious learning or modeling, emotional arousal (anxiety), and social persuasion and encouragement were important to the initial development of self-efficacy expectations. The findings of this study highlight the importance of preservice teachers' personality characteristics, capabilities, and motivation as potential sources of teaching efficacy.

Also, the results of Pearson product-moment correlations in this study indicated that efficacy for efficacy for instructional strategies, classroom management, and student engagement were significantly related to each other in the pre-test data for this sample of preservice teachers in the United States. This implies that the three self-efficacy dimensions together measure a single underlying latent construct of self-efficacy.

Teacher self-efficacy is a crucial factor in improving teacher education and promoting education reform because high teacher self-efficacy consistently has been found to relate to positive student and teacher behaviors. Thus, teacher educators need to consider all sources of information that influence prospective teachers' efficacy beliefs if prospective teachers' efficacy is to be enhanced during teacher education programs. For high levels of prospective teachers' efficacy, university teacher education programs should provide positive information from vicarious experience, social persuasion, and a form of mastery experience offered by student colleagues, cooperating teachers, and university supervisors. In addition, the fact that the three dimensions of self-efficacy were highly intercorrelated suggests that future research in this area could be undertaken using structural equation modeling approaches in which self-efficacy is treated as a latent trait with three underlying constructs.

\section{References}

Anderson, S., \& Betz, N. (2001). Sources of social self-efficacy expectations: Their measurement and relation to career development. Journal of Vocational Behavior, 58, 98-117. doi:10.1006/jvbe.2000.1753

Bandura, A. (1977). Self-efficacy: Toward a unifying theory of behavioral change. Psychological Review, 84, 191-215. doi:10.1037/0033-295X.84.2.191

Bandura, A. (1997). Self-efficacy: The exercise of control. New York: W. H. Freeman.

Chan, D. W. (2008). General, collective, and domain-specific teacher self-efficacy among Chinese prospective and in-service teachers in Hong Kong. Teaching and Teacher Education, 24, 1057-1069. doi:10.1016/j.tate.2007.11.010

Dembo, M. H., \& Gibson, S. (1985). Teachers' sense of efficacy: An important factor in school improvement. The Elementary School Journal, 86, 173-184. doi:10.1086/461441

Erdle, S., Murray, H. G., \& Rushton, J. P. (1985). Personality, classroom behavior, and student ratings of college teaching effectiveness: A path analysis. Journal of Educational Psychology, 77, 394-407. doi: $10.1037 / 0022-0663.77 .4 .394$

Henson, R. K. (2001, February). Relationships between preservice teachers' self-efficacy, task analysis, and classroom management beliefs. Paper presented at the annual meeting of the Southwest Educational Research Association, New Orleans, LA.

Poulou, M. (2007). Personal teaching efficacy and its sources: student teachers' perceptions. Educational Psychology, 27, 191-218. doi: $10.1080 / 01443410601066693$

Tschannen-Moran, M., \& Woolfolk Hoy, A. (2001). Teacher efficacy: Capturing an elusive construct. Teaching and Teacher Education, 17, 783-805. doi:10.1016/S0742-051X(01)00036-1

Tschannen-Moran, M., \& Woolfolk Hoy, A. (2007). The differential antecedents of self-efficacy beliefs of novice and experienced teachers. Teaching and Teacher Education, 23, 944-956. doi:10.1016/j.tate.2006.05.003

US Department of Education, Office of Elementary and Secondary Education. (2002). No Child Left Behind: A desktop reference. Washington, DC.

Yeung, K. W, \& Watkins, D. (2000). Hong Kong student teachers' personal construction of teaching efficacy. Educational Psychology, 20, 213-235. doi:10.1080/713663713 